\title{
The Effect of Interval Training Sets of Maximal Intensity on Metabolic Markers in Master Swimmers ${ }^{+}$
}

\author{
Athanasios Kabasakalis *, Stefanos Nikolaidis, George Tsalis and Vassilis Mougios \\ Laboratory of Evaluation of Human Biological Performance, School of Physical Education and Sport Science, \\ Aristotle University of Thessaloniki, 54124 Thessaloniki, Greece \\ * Correspondence: athankab@gmail.com \\ + Presented at the 9th Greek Conference of Biochemistry and Physiology of Exercise, Thessaloniki, Greece, \\ 18-20 October 2019.
}

Published: 29 August 2019

\begin{abstract}
Aim: Regular swimming training is gaining popularity among adults for health and competition. The acute effects of high-intensity interval swimming are largely unknown in such populations. Thus, the aim of the present study was to evaluate the effects of swimming training sets of maximal intensity and different volumes on blood metabolic markers in master swimmers. Material \& Method: Twenty-one master swimmers (11 females and 10 males), aged 40.5 (7.4) years, completed two freestyle swimming sets of $4 \times 50 \mathrm{~m}$ and $4 \times 25 \mathrm{~m}$ at maximal intensity and a work-to-rest ratio of 1:1 on different days, in random and counterbalanced order. Blood samples were taken before, immediately after and one hour after exercise for determination of glucose and uric acid (at all three time-points, spectrophotometrically), as well as irisin, insulin, glucagon, and cortisol (pre- and immediately post-exercise, through enzyme immunoassays), in plasma. Data were analyzed through three-way analysis of variance (set $\times$ time $\times$ gender). Statistical significance was declared when $p<0.05$. Results: Glucose was higher immediately post-exercise compared to pre- and $1 \mathrm{~h}$ post-exercise $(p<0.001)$. Uric acid increased $1 \mathrm{~h}$ post-exercise $(p<0.001)$ and exhibited a time $\times$ gender interaction $(p=0.029)$ due to a larger increase in males. Irisin showed a time $\times$ gender interaction $(p=0.028)$, as exercise caused an increase in females and a decrease in males. Insulin increased with exercise $(p<0.001)$ and was higher in females $(p=0.016)$. Set $\times$ time interactions found in glucose, uric acid, and insulin denoted larger increases with the $4 \times 50$ set $(p<$ $0.05)$. Glucagon increased with exercise $(p=0.014)$. Cortisol increased with exercise in males and more with the $4 \times 50$ set, as set $\times$ time and time $\times$ gender interactions and a main effect of time were found $(p<0.05)$. Conclusions: Interval swimming training sets of maximal intensity induced increases in plasma glucose, uric acid, insulin, glucagon, and cortisol in master swimmers. The larger set volume induced larger increases, which may have implications for the magnitude of the desired adaptations to training.
\end{abstract}

Keywords: exercise metabolism; interval training; master swimmers

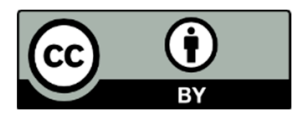

(C) 2019 by the authors. Licensee MDPI, Basel, Switzerland. This article is an open access article distributed under the terms and conditions of the Creative Commons Attribution (CC BY) license (http://creativecommons.org/licenses/by/4.0/). 